\title{
下顎枝矢状分割法における術中偶発骨折とその対策
}

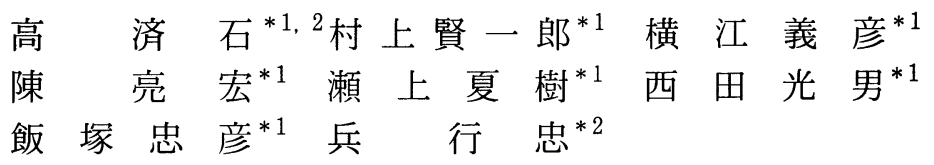

\section{Perioperative Unfavorable Fracture in the Sagittal Splitting Ramus Osteotomy and its Management}

\author{
SAISEKI KO*1 2 , Ken-IChiRo MURAKAMI*1, Yoshihiko YOKOE*1, \\ LiAnq-Horng CHEN ${ }^{* 1}$, NAtSUKi SEGAMI*1, Mitsuo NISHIDA*1, \\ TADAHIKo IIZUKA ${ }^{* 1}$ and YUKITADA HYO ${ }^{* 2}$
}

\begin{abstract}
Sagittal splitting ramus osteotomy is widely performed for correction of mandibular skeletal dentofacial deformities. We retrospectively studied 325 patients treated with bilateral sagittal splitting ramus osteotomies in order to investigate perioperative unfavorable fracture, and found eight episodes of fracture in eight patients (2.4\% of incidence). The most predominant fracture site was the distal segment with vertical and horizontal fracture line. All fractured segments were sufficiently repositioned and fixed in appropriate positions. Slight extension of the intermaxillary fixation period was noted, however, no severe postoperative complication was found.

It was considered that incomplete osteotomy, misdirection of horizontal medial osteotomy, and violent bone split caused unfavorable fractures.
\end{abstract}

Key words： sagittal splitting ramus osteotomy (下顎枝矢状分割法)， complication (合併症)， unfavorable fracture (偶発骨折)

[Received Dec. 26, 1994]

緒言

下頡枝矢状分割法は，顎変形症に対する外科的 矯正手術において広く選択される術式であるが, 稀に術中偶発骨折，下歯槽神経支配領域の知覚異 常, 顔面神経麻瘏, 術中の多量出血等の合併症を 伴うことがある ${ }^{1)}$ 。今回われわれは，その中の特に 術中偶発骨折について調査するとともに，その骨 折要因および対策について検討したので報告する。

\section{対象および方法}

1984年 1 月から1993年12月までの10年間に当科 に扔いて施行した顎変形症手術のらち下顎枝矢状 分割法を実施した325症例（650側）について，診 療録，手術記録ならびに術前後のエックス線写真 に基づき術中偶発骨折の有無を調查した。さらに 術中偶発骨折例について，骨折部位と骨折様態， 手術術式の詳細，偶発骨折への対処と骨折骨片の

*1 京都大学医学部口腔外科学教室 (主任 : 飯塚忠彦教授)

*2 国立京都病院歯科口腔外科（主任：兵 行忠医長）

*1 Department of Oral and Maxillofacial Surgery, Faculty of Medicine, Kyoto University (Chief : Prof. Tadahiko IIZUKA)

*2 Department of Dentistry and Oral Surgery, Kyoto National Hospital (Chief : Yukitada HYO) 

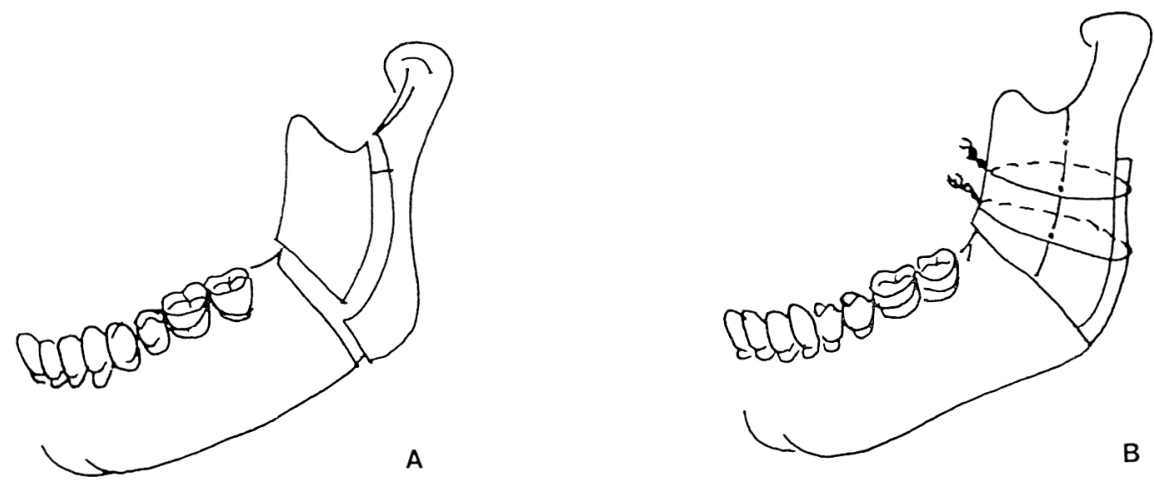

Fig. 1 (Case 1) Shemas of pre-(A), and post-(B) fixation of fractured segment.
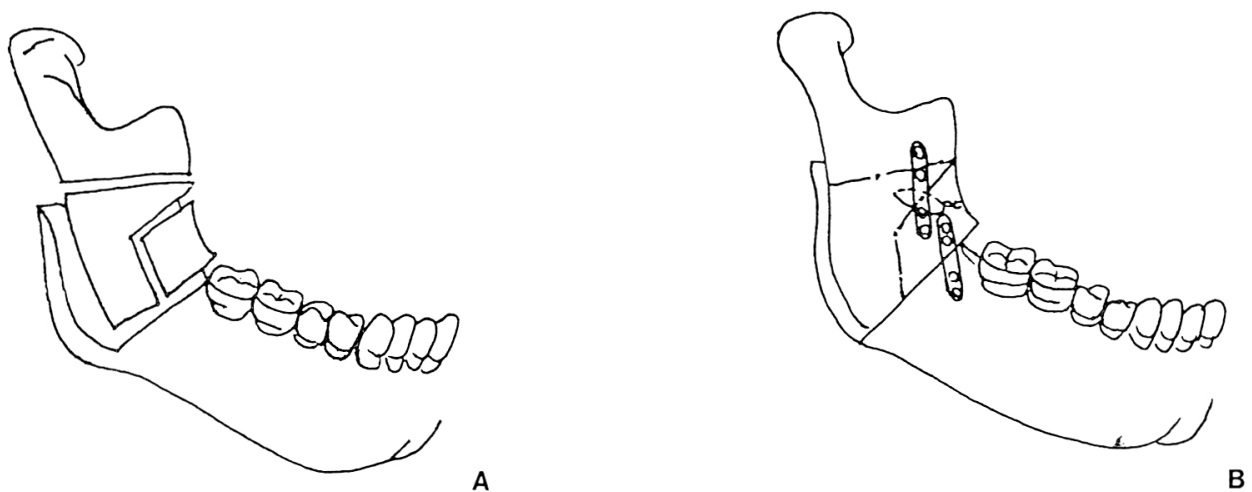

A

B

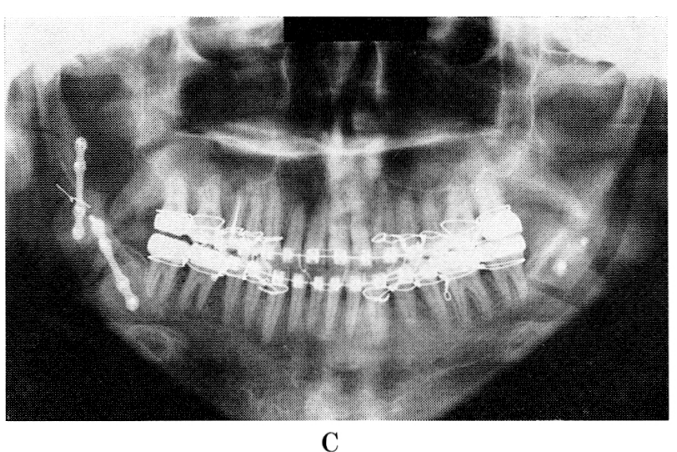

Fig. 2 (Case 7) Shemas of pre-(A), and post-(B) fixation of fractured segment, and post operative radiograph $(\mathrm{C})$.

固定方法，手術時間，䫟間固定の期間，袒間固定 解除後の臨床経過について検討した。

\section{結果}

325 症例のらち術中偶発骨折を認めたのは 8 症例 （8 側）で，発生頻度は $2.4 \%$ であった。骨折部位 は，8 例中 6 例が外側骨片に，2 例が内側骨片に
認められた。左右差は，特に認めなかった。また， 偶発骨折は，いずれも分割ノミにより内外側骨片 を分割する際に発生していた。

骨折の様態をみると，外側骨片の骨折は，(1) 下顎切痕から外側骨切り線に至る下顎枝を縦断す る骨折 (Fig. 1A)，(2) 内側骨切り線の高さで下 顎枝を横断する骨折 (Fig. 2A)，(3) これらを複 

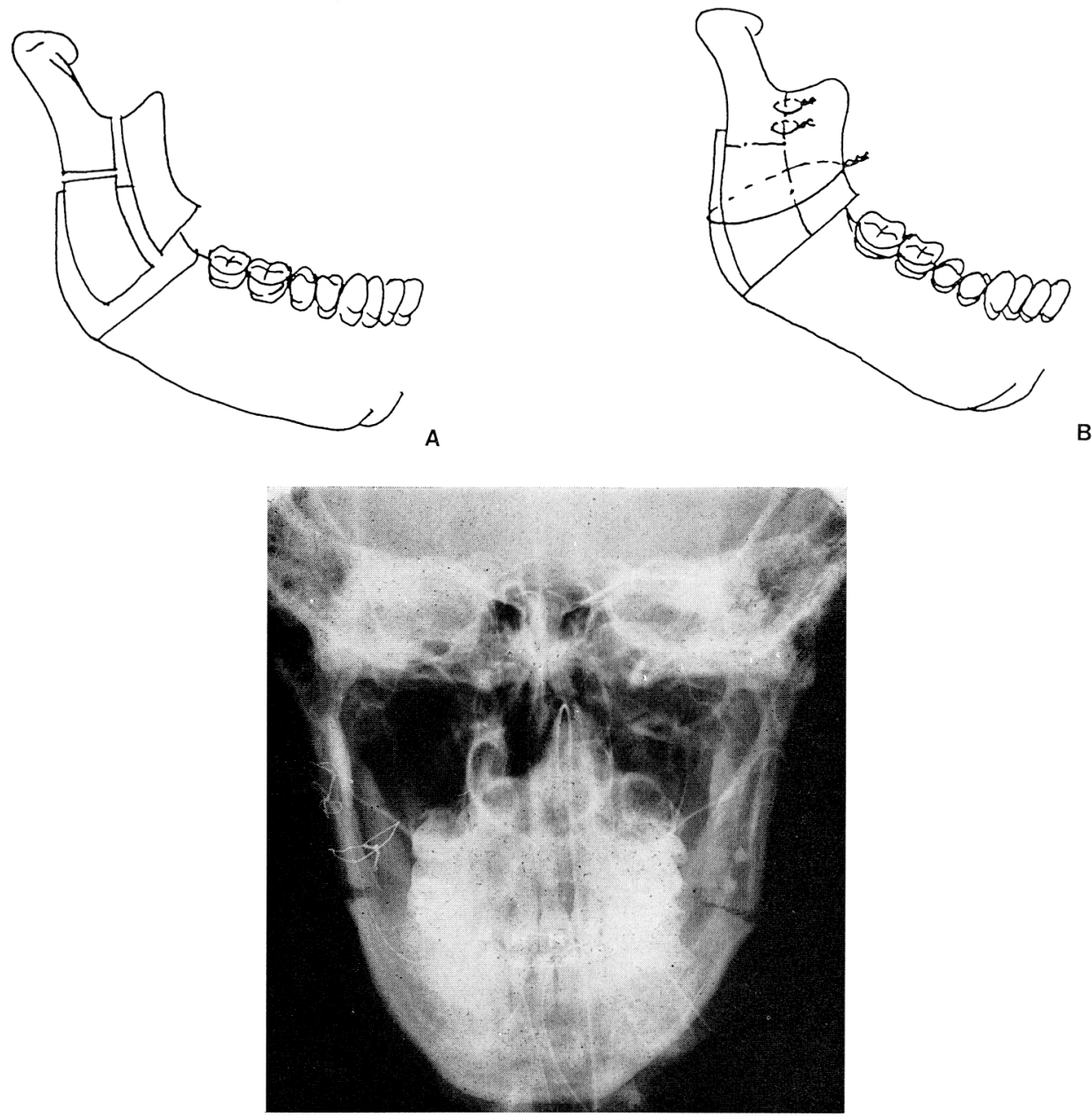

C

Fig. 3 (Case 5) Shemas of pre-(A), and post-(B) fixation of fractured segmant, and post operative radiograph (C).

合した骨折 (Fig. 3A)，(4) 内側骨切り線と外側 骨切り線の間で下顎枝を横断する骨折に分類する ことができた。一方内側骨片では，(5) 内外側骨 切り線の間で下䞄枝を横断する骨折 (Fig. 4A), そして（6）埋伏智歯部での骨折が認められた。

骨折した骨片の固定は，ワイヤーによる囲繞結 禁, 骨縫合, スクリュー固定, さらにミニプレー トによる種々の固定法が行われていた（Table 1, Fig. 1 4B, 2C, 3C)。

手術時間は, 最短 4 時間 5 分, 最長 6 時間 40 分, 平均で 5 時間 26 分を要していた。出血量は, 最少 $250 \mathrm{~g}$, 最多 $730 \mathrm{~g}$, 平均で $526 \mathrm{~g}$ であった。しかし
輸血を必要とした症例はなかった。

術後の顎間固定期間は最短 18 日間, 最長 8 週間 行っていた（Table 2)。顎間固定中または解除後 に感染した症例はなく，また骨折の癒合不全ある いは偽関節などの合併症を生じた症例もなかった。 顎間固定解除後の下䫟の後戻りに対しての臨床 的対処法を，診療録から検討した。その結果 8 例 中 4 例に軽度の後戻りの記載があり,これに対し ては通常の術後歯科矯正治療とチンキャップの装 用により制御され，後戻りのために再手術を要し た症例はなかった。

症例 $2,3,4,6$ では術後オトガイ部の知覚異 
Table 1 Site of fractured segment and method of fixation for patients with perioperative unfavorable fracture

\begin{tabular}{|c|c|c|c|c|}
\hline case & age & sex & site of fractured segment & procedure of bone fixation \\
\hline 1 & 26 & $\mathrm{~F}$ & lt-distal segment & two circumferential wirings \\
\hline 2 & 33 & M & $\begin{array}{l}\text { lt-proximal segment, } \\
\text { wisdom tooth region }\end{array}$ & $\begin{array}{l}\text { circumferential wiring } \\
\quad+\text { screw synthesis }\end{array}$ \\
\hline 3 & 24 & $\mathrm{~F}$ & rt-distal segment & $\begin{array}{l}\text { circumferential wiring } \\
\quad+\text { four wire osteosyntheses }\end{array}$ \\
\hline 4 & 25 & $\mathrm{M}$ & rt-distal segment & three screw syntheses \\
\hline 5 & 20 & $\mathrm{M}$ & rt-distal segment & $\begin{array}{l}\text { circumferential wiring } \\
\quad+\text { two wire osteosyntheses }\end{array}$ \\
\hline 6 & 27 & M & lt-proximal segment & $\begin{array}{l}\text { two mini-plate osteosyntheses } \\
\quad \text { + screw synthesis } \\
\text { + wire osteosynthesis }\end{array}$ \\
\hline 7 & 28 & $\mathrm{~F}$ & rt-distal segment & $\begin{array}{l}\text { two mini-plate osteosyntheses } \\
\quad \text { + wire osteosynthesis }\end{array}$ \\
\hline 8 & 21 & $\mathrm{~F}$ & rt-distal segment & $\begin{array}{l}\text { mini-plate osteosynthesis } \\
\quad+\text { screw synthesis }\end{array}$ \\
\hline
\end{tabular}

F : Female, M : Male, lt : left, rt : right
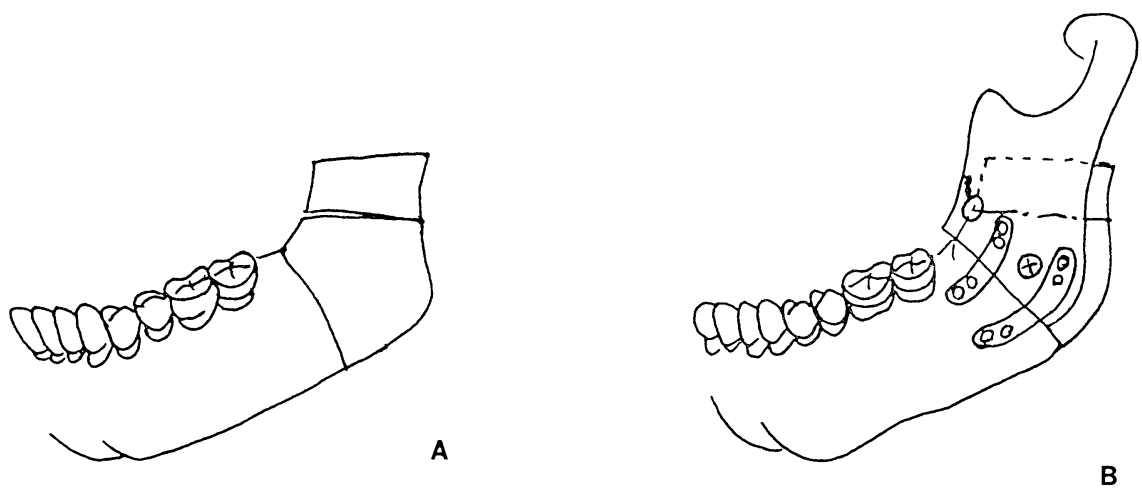

Fig. 4 (Case 6) Shemas of pre-(A), and post-(B) fixation of fractured segment.

常を，症例 3 では術後右側顔面神経の不全麻痺を 認めたが，外来での保存的加療により術後 6 力月 で軽快していた。

\section{考察}

下顎枝矢状分割法は顎変形症手術において広く 選択される術式の 1 つであるが，その術中合併症 についての報告は多くない。

O'Ryan ${ }^{11}$ は，術中偶発骨折の様態について， （1）外側骨片の外側骨切り線上での骨折，(2) 下 顎枝後縁あるいは下縁部での骨折，（3）外側骨片 を横断する骨折，(4) 内側骨切り線に沼った外側 骨片の水平骨折，（5）外側骨切り線に沿った内側
骨片の垂直骨折などを挙げている。今回検討した 8 症例の骨折様態もこれらとほぼ類似しているが, 3 症例においては下顎切痕から外側骨切り線に至 る外側骨片の前後的中央を縦断する骨折を認め, 水平的および垂直的骨折を複合したより複雑な骨 折様態がみられたことが特徴的であった。しかし 骨折は内外側骨片のいずれかにのみ生じ，両骨片 にわたって偶発骨折を生じた症例は認めなかった。 このことは，分割操作時の過度の応力が，不完全 な骨切り部あるいは不適切な骨切り設定線に集中 することにより偶発骨折が生じることを示してい ると考えられた。

飯塚ら ${ }^{2)}$ は，顎変形症に対する外科的矯正手術 
Table 2 Operating time, volume of blood loss, period of intermaxillary fixation, and episodes of relapse and its management

\begin{tabular}{cccccc}
\hline case & $\begin{array}{l}\text { operating } \\
\text { time }\end{array}$ & $\begin{array}{l}\text { volume of } \\
\text { blood loss }\end{array}$ & $\begin{array}{l}\text { period of } \\
\text { intermaxillary } \\
\text { fixation }\end{array}$ & $\begin{array}{l}\text { episodes of } \\
\text { relapse }\end{array}$ & $\begin{array}{c}\text { post operative } \\
\text { orthodontics }\end{array}$ \\
\hline 1 & $4 \mathrm{~h} 05 \mathrm{~m}$ & 550 & 43 & + \\
2 & $5 \mathrm{~h} 10 \mathrm{~m}$ & 720 & 30 & + & follow up \\
3 & $5 \mathrm{~h} 07 \mathrm{~m}$ & 250 & 52 & + & + \\
4 & $5 \mathrm{~h} 45 \mathrm{~m}$ & 500 & 45 & + & + \\
5 & $5 \mathrm{~h} 05 \mathrm{~m}$ & 530 & 56 & + \\
6 & $5 \mathrm{~h} 30 \mathrm{~m}$ & 270 & 18 & \\
7 & $4 \mathrm{~h} 44 \mathrm{~m}$ & 730 & 37 & & + \\
8 & $6 \mathrm{~h} 40 \mathrm{~m}$ & 660 & 38.5 days & & + \\
\hline average & 5 hours & $526 \mathrm{~g}$ & & & \\
\end{tabular}

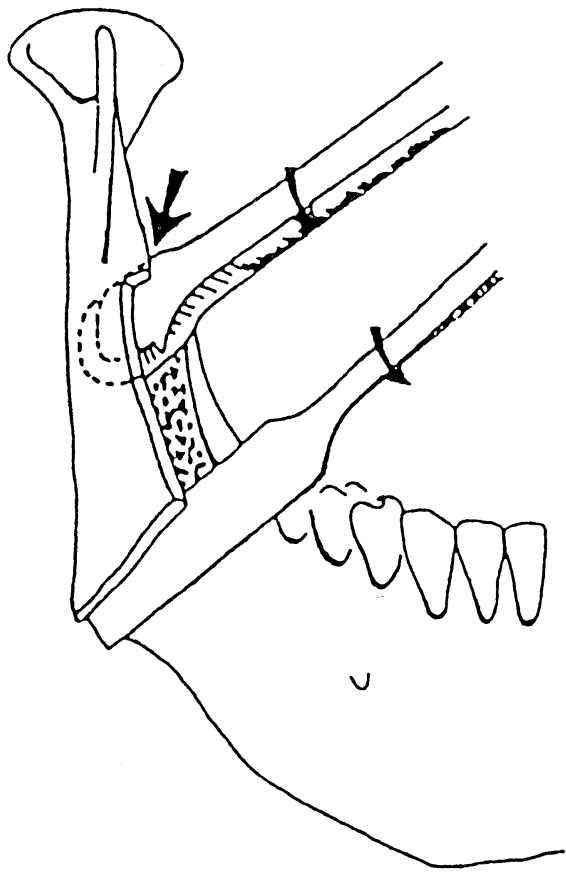

Fig. 5 Inserting the wedging osteotome partially above the horizontal osteotomy line prevents outfracturing of the buccal cortical plate at this level. (Mommaerts) 1992)

における手術時間と術中出血量について検討して いるが，下顎枝矢状分割法単独施行例44例におい ては, 平均手術時間 3 時間 11 分, 平均術中出血量 $461.4 \mathrm{~g}$ であったと報告している。その他諸家の 報告と比較しても，今回検討した術中偶発骨折を
生じた 8 症例では，平均手術時間 5 時間 26 分，平 均出血量526gであり，いずれも延長，増加してい た。術中偶発骨折は，手術時間の延長，術中出血 量の増加，そして術後顎閒固定期間の延長などを 伴うことからも，下顎枝矢状分割法における避け るべき合併症の 1 つと考えられた。

Smith $ら^{31}$ は本手術施行時の術中偶発骨折の要 因として，(1）不完全な骨切り，(2）大きすぎる 骨ノミの使用，（3）拙速な分割，（4）埋伏智歯の 存在, (5) 内側骨切り線の後方への角度が誤って 過度に下顎頭の方向へ向いたり，(6) 内側骨切り 線が過度に高位に設定されることなどを挙げてい る。さらに(6) については，高位になればなるほ ど煩舌側の皮質骨の間に海綿骨組織が介在しない ため分割は困難になると述べている。今回の 8 症 例の骨折要因を検討したところ, 内外側の骨切り が後縁まで確実になされない不完全な骨切りであ ったり，拙速な分割がおこなわれた場合，あるい は骨切り線を誤って高位に設定した例，さらに埋 伏智歯が存在したままでの無理な分割などが偶発 骨折を誘発する大きな因子になったと考えられた。 この他, 症例 4 では, 過去に下顎枝部に放射線外 照射を受けており同部の骨がそ血性変化を起こし ていたことが，術中偶発骨折を誘発したと考えら れた。

術中偶発骨折を防止する 1 つの方法として

Mommaerts $^{4)}$ は，内側骨切り線上に大きな骨） ミを沿わせて分割するとよいと述べている（Fig. 
5)。Carlton ら ${ }^{5)}$ は，下顎下縁平面角が大きい症 例では，内側骨切り線の設定に際して，下顎咬合 平面の傾斜角よりやや上方へ角度をつけて骨切り を行うことを推奨している。また Nishioka ら6) は，内側骨切りにあたって十分な皮質骨切りを加 えること，また可及的に下顎枝下方で骨切りを行 らことを勧めている。われわれの経験では術中偶 発骨折は，内側または外側骨片いずれの骨折にか かわらず，内側骨片の骨切りの過不足あるいは骨 切り線の設定の誤りが原因と考えられた症例が多 かった。したがって術中偶発骨折の防止には，骨 切り線の設定を誤らず, 内外側の骨切りを確実に 行い, 分割操作を注意深く施行し，もし分割時に 過剰の応力が術者の手指に触知されれば, 骨切り 部とその設定部の再確認を行うことが肝要である と考えられた。

\section{結 語}

1984年 1 月から 1993 年 12 月までの 10 年間に当科 において施行した下顎枝矢状分割法 325 症例のう ち術中偶発骨折の合併症を生じた 8 症例について
調査し，骨折要因および対策について検討したの で報告した。

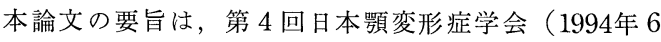
月 3 日，鹿児島）に掠いて発表した。

\section{文献}

1) O'Ryan, F.: Complications of orthognathic surgery, Oral Maxillofac Surg Clin North Am 2: 593-613, 1990.

2）飯塚忠彦, 他: 各種顎変形症に対する外科的矯正術術 中出血量と手術時間についての検討, 日口外誌，28： 1956-1963, 1982.

3) Smith, B. R., et al: Mandibular ramus anatomy as it relates to the medical osteotomy of the sagittal split ramus osteotomy, J Oral Maxillofac Surg 49: 112-116, 1991.

4) Mommaerts, M. Y.: Two similar " bad splits" and how they were treated. Int J Oral Maxillofac Surg $21:$ 331-332, 1992.

5) Carlton, A. S., et al: Prevention of the misdirected sagittal split, J Oral Maxillofac Surg 44 : 81-82, 1986.

6) Nishioka, G. J., et al: Modified sagittal split technique for patients with a high lingula, J Oral Maxillofac Surg 47:426-427, 1989. 